\title{
MEMELIHARA RIAK SASTRA SUNDA
}

\author{
Dian Hendrayana \\ Universitas Pendidikan Indonesia, dianhendrayana71@gmail.com
}

\begin{abstract}
ABSTRAK
Sastra merupakan wahana untuk mengekspresikan sebuah situasi tertentu pada periode tertentu pula melalui tafsir dan kacamata sastrawan. Dengan pengertian lain, sastra bisa menjadi media perekaman sosial kemasyarakatan tertentu untuk dibaca, ditelaah, dan dijadikan acuan untuk membentuk suasana serta karakter masyarakatnya di kemudian hari. Sastra Sunda tentu saja merupakan rekaman dari situasi kehidupan sosial masyarakat Sunda. Sastra Sunda bisa menjadi media dan menjadikannya album sosial kemasyarakatan untuk ditelaah dan dijadikan pijakan demi menunaikan pola sosial kemasyarakatan di kemudian hari bagi masyarakat Sunda yang lebih berkembang dan maju. Sementara itu, nyaris di setiap sudut, pengaruh asing seolah berlomba-lomba merangsek ke masyarakat kita. Tak terkecuali di masyarakat Sunda. Berkembangnya dunia teknologi, serta merta akan mampu mengubah cara bersikap dan berfikir bagi masyarakat agar tetap melaju sesuai dengan kebutuhan dan perkembangan zamannya.Persoalannya adalah, bagaimana masyarakat Sunda mampu memelihara dan mempertahankan keberadaan sastra Sunda sebagai media rekam masyarakatnya. Padahal, di samping upaya pemeliharaan dan pelestarian keberadaan sastra, baik tulis maupun lisan, pengaruh asing tadi begitu deras menerjang tatanan sosial kemasyarakatan di tatar Sunda. Sebagai sebuah entitas yang serta-merta bisa memorak-porandakan keberadaan sosial masyarakat, maka pengaruh asing itu jelas harus disikapi dengan hati-hati dan pikiran bijak.Tentu saja, upaya-upaya dengan cara bekerja keras dan upaya-upaya konstruktif harus segera dilakukan. Pemberlakuan upaya ini tentu dengan melibatkan berbagai pihak, lembaga-lembaga terkait baik pemerintah maupun swasta.
\end{abstract}

Kata kunci: sastra Sunda, media, pengarang, pembinaan, saembara, pemerintah, pihak swasta 


\section{PENDAHULUAN}

Setidaknya masyarakat Sunda telah mengenal keberadaan sastranya sejak leluhurnya menuliskan dokumentasi pada sebuah naskah (Sunda kuna) yang bernama Sanghyang Siksakanda (Ng) Karesyan (SSKK) * Naskah Sunda kuno tersebut ditulis pada tahun $1518 \mathrm{M}$. Melalui dokumentasi kuno yang oleh para ahli disebut sebagai 'ensiklopedi' budaya Sunda (kuno) tersebut masyarakat Sunda diperkenalkan bahwa pada saat itu masyarakat Sunda telah mengenal materi sastra (lisan) seperti kawih (sebetuk puisi bebas), cerita pantun (kisah panjang seputar kerajaan), sisindiran (sebentuk pantun pada sastra melayu, atau parikan pada sastra Jawa), cerita wayang, dan mantra.

Materi-materi sastra yang (telah hidup sebelum abad XVI, dan) tertuang pada naskah SSKK tersebut terus hidup dan berkembang di masyarakat pada tahun-tahun serta abad-abad kemudian. Dari materi-materi sastra tersebut di antaranya ada yang berfungsi sebagai media hiburan (sisindiran, cerita wayang, kawih) ada juga yang berfungsi sebagai media ritual (cerita pantun, mantra). Seiring dengan perkembangannya, di sekitar abad XVII saling menyusul materimateri sastra asing yang datang dari luar, yakni dari pengaruh Islam dalam bentuk syair yang kemudian berkembang menjadi pupujian ${ }^{\dagger}$, serta dari pengaruh Mataram yang berbentuk dangding $\$$ yakni puisi yang terbangun dari aturan pupuh: terutama bentuk wawacan (Wibisana, 1992:765).

\footnotetext{
* Naskah SSKK memuat 30 bagian, setiap bagian menerangkan bab tertentu tentang budaya, adat kebiasaan, kesenian, keterampilan, serta peradaban yang ada di masyarakat Sunda saat itu

+ Pupujian (puisi untuk memuja-muhi sang khalik dan rosululloh), adalah syair dalam bahasa Arab dan (telah diterjemahkan ke dalam) bahasa Sunda biasa dilantunkan di surau atau di mesjid menjelang kumandang adzan Magrib

‡ Dangding adalah puisi yang terbangun dengan menggunakan aturan pupuh. Dalam puisi Sunda dangding dibagi menjadi dua jenis yakni wawacan dan guguritan; wawacan adalah cerita atau kisah yang ditulis dengan aturan pupuh (memuat ratusan bahkan ribuan bait), sedangkan
}

252 | http://journal.unesa.ac.id/index.php/paramasastra 
Hingga abad XIX, materi sastra yang masih berkembang di masyarakat adalah cerita pantun, pupujian, sisindiran, dan dangding. Bahkan di sepanjang abad XIX, materi dangding (berbentuk wawacan) memiliki tempat tersendiri di masyarakat Sunda. Hal itu terbukti dengan tradisi menembangkan wawacan di beberapa daerah di Jawa Barat seperti Cianjur, Bandung, Tasikmalaya, Garut, Sumedang, dan Ciamis. Terlebih di daerah Cianjur, Garut, dan Tasikmalaya, materi sastra dalam bentuk dangding wawacan terus berkembang hingga awal abad XX; hal itu terbukti dengan masih berkembangnya materi seni tembang Cianjuran (di daerah Cianjur), tembang Ciawian (daerah Tasikmalaya), dan tembang Cigawiran (daerah Garut).

Di awal abad XX, materi dangding dalam bentuk guguritan mulai digandrungi, terutama oleh masyarakat daerah Cianjur. Di Cianjur sendiri materi guguritan kerap dijadikan bahan dasar untuk pembentukan (dan pengayaan) materi seni tembang Cianjuran yang saat itu tengah menjadi trending topic dalam percaturan khazanah seni Sunda. Para pangagung (bangsawan) di Cianjur banyak yang meminati seni Cianjuran dengan berbahan puisi guguritan sebagai lirikliriknya (Sukanda, 2016:126).

Tentang materi guguritan ini, hingga pertengah paruh pertama abad XX, telah membuat opini masyarakat Sunda yang beranggapan bahwa puisi guguritan merupakan puisi yang sangat agung dan paling bagus dari puisi-puisi yang pernah ada. Bahkan beberapa sastrawan menganggap jika dalam mengekspresikan pikirannya tidak membubuhkan materi guguritan, maka materi sastra tersebut tidak lantas disebut memiliki nilai sastra tinggi. Sebaliknya, jika ekspresi sastra (termasuk prosa) disertai dengan membubuhkan puisi guguritan, maka karya itu serta-merta akan tergolong menjadi karya yang memiliki nilai sastra tinggi

guguritan adalah ungkapan perasaan atau ekspresi jiwa yang ditulis dengan aturan pupuh (biasanya hanya terdiri atas lima atau enam bait saja) 
(Rosidi, 2013: 79). Dan pada masa itu, puisi guguritan seperti menempati setiap relung kegiatan di masyarakat Suna; berpidato menggunakan puisi guguritan, surat-menyurat menggunakan puisi guguritan, mengobrol (di kalangan tertentu) menggunakan puisi guguritan. Dan semua itu menyebar pula di setiap segi kehidupan kaum bangsawan di lingkungan pendopo (kadaleman); termasuk terhadap materi seni Cianjuran yang saat itu hanya beredar di kalangan kaum bangsawan di Cianjur dan di Bandung.

Bahkan hingga dekade 60-an, seni Cianjuran dengan menggunakan lirik puisi guguritan menjadi materi yang bukan hanya milik kaum bangsawan di lingkungan pendopo, tetapi sudah digandrungi dan diminati oleh hampir seluruh masyarakat jawa Barat, terutama di daerah Cianjur, Bogor, Bandung, Sumedang, Garut, Tasikmalaya, dan Ciamis. Maka hingga tahun 1960-an, banyak sastrawan Sunda yang menuliskan karya-karyanya dalam bentuk puisi guguritan.

Kegandrungan para sastrawan Sunda terhadap puisi guguritan kemudian sempat memunculkan polemik tersendiri, ketika Wahyu Wibisana (1. 1939, wafat 2014) memperjuangkan puisi jenis baru yang cenderung lebih bebas dalam berkespresi ${ }^{\S}$ (Rosidi, 2013: 87). Puisi baru tersebut adalah sajak. Adapun polemik (satu pihak mempertahankan puisi guguritan, pihak lain menyuarakan materi baru berbentuk sajak) tersebut, dimuat dan didokumentasikan oleh majalah Warga yang terbit pada paruh awal dekade 50-an. Dalam perkembangannya, puisi guguritan dan puisi berbentuk sajak hidup dan berkembang secara beriring berdampingan.

Selain ekspresi sastra dalam bentuk puisi guguritan dan sajak, dalam khazanah sastra Sunda pun hidup karya sastra dalam bentuk carpon (carita

\footnotetext{
$\S$ Wahyu Wibisana pada dekade 50 -an merupakan sastrawan yang sangat gigih memperjuangkan karya sajak untuk diterima di masyarakat, meskipun harus bersitegang dengan kelompok yang mempertahankan puisi guguritan. Materi sajak itu sendiri baru muncul dalam khazanah sastra Sunda sekitar tahun 1946, ditandai dengan pemuatan karya sajak Ilangna Mustika karya Kis WS pada majalah....
}

254 | http://journal.unesa.ac.id/index.php/paramasastra 
pondok, cerita pendek). Karya prosa dalam bentuk carpon ini dimulai di awal abad XX ketika pada tahun 1914 terbit buku kumpulan carpon pertama, yakni Dogdog Pangréwong karya GS. Terhadap ekspresi sastra berbentuk carpon ini, para pengarang Sunda cukup menggandrungi pula. Serta dalam perkembangannya tidak memunculkan polemik di kalangan sastrawan dan masyarakat seperti halnya yang terjadi pada polemik guguritan dan sajak. Bahkan sejak sebelum kemerdekaan, para sastrawan Sunda telah banyak mengekspresikan buah pikirannya dalam bentuk carpon yang saat itu lebih dikenal sebagai roman (Rosidi, 2013: 132). Dalam makalah inipun, penulis mengadakan penelitian ringan berdasarkan ketiga ekspresi sastra tadi, yakni sajak, guguritan, dan carita pondok (carpon).

\section{PEMBAHASAN}

Ekspresi sastra yang masih hidup hingga sekarang adalah sajak, carpon, guguritan, novel (dalam bentuk carita nyambung; bs. Indonesia: cerita bersambung), dan naskah drama. Namun jika dilihat dari produktivitas penerbitannya, naskah berupa carpon, sajak, dan guguritan lebih tumbuh dengan subur.

Keberlangsungan ekspresi sastra Sunda itu tidak lepas dari beberapa faktor, yakni media massa (terutama media cetak), pengarang, dan stimulan. Dalam upaya pemeliharaan kesastraan Sunda, ketiga faktor ini saling melengkapi dan bertalian erat satu sama lainnya. Jika salah satunya timpang, maka lajunya pemeliharaan dan perkembangan kesastraan Sunda akan mengalami ketimpangan pula.

Media Massa

Dalam sepuluh tahun terakhir, media massa yang biasa memuat karya sastra adalah majalah (mingguan) Mangle, majalah (bulanan) Sunda midang, 
tabloid (mingguan) Galura, Majalah (bulanan) Cupumanik, koran (harian umum) Pikiran Rakyat, dan koran (harian pagi) Tribun Jabar .

Majalah Mangle adalah media massa berbahasa Sunda yang banyak memuat karya sastra berbentuk carpon (carita pondok, cerpen). Bisa dihitung dan dibayangkan, dalam satu minggu (satu edisi), majalah Mangle biasa menyajikan rata-rata enam carpon (termasuk carpon misteri dan carpon lucu). Maka dalam sebulan, majalah Mangle rata-rata bisa menyajikan 24 buah carpon. Jumlah itu, dalam setahun bisa menjadi 228 (dua ratus dua puluh delapan) carpon.

Tabloid Galura, dalam satu edisi (mingguan) memuat satu carpon. Maka dalam sebulan, tabloid Galura bisa memuat empat carpon. Dalam setahun, tabloid Galura akan menyumbang 48 carpon. Sementara, majalah Cupumanik dan majalah Sunda Midang (majalah bulanan), dalam setiap terbitannya akan memuat empat carpon. Maka dalam sebulan, kedua majalah bulanan tersebut akan menyumbang delapan carpon. Serta dalam setahun akan menyumbang 96 (sembilan puluh enam) carpon.

Sementara itu, koran Tribun Jabar, pada setiap minggunya juga menyajikan satu carpon. Artinya, dalam setahun, koran Tribun Jabar akan menyumbang 48 carpon. Sementara koran Pikiran Rakyat, dalam tiga bulan sekali menyajikan sartu carpon. Artinya dalam setahun, koran Pikiran Rakyat menyumbangkan paling tidak empat carpon.

Jika dijumlahkan, dalam satu tahun media massa yang ada di Jawa Barat (Bandung) memuatkan $228+48+96+48+4=354$ carpon. Jumlah pemuatan dalam setahun sebanyak itu cukup menentramkan bagi terciptanya riak sastra Sunda dalam penulisan carpon.

Untuk lebih jelasnya, jumah penulisan carpon pada media massa jika dilihat dalam kurun waktu satu tahun bisa dilihat pada tabel di bawah ini: 
Dian Hendrayana, Memelihara Riak Sastra... (hlm. 251-265)

\begin{tabular}{|l|l|l|l|}
\hline \hline \multirow{2}{*}{ Media } & \multicolumn{2}{|l|}{ Banyaknya Pemuatan } & \multirow{2}{*}{ Jumlah Setahun } \\
\cline { 2 - 3 } & Mingguan & Bulanan & \\
\hline Majalah Mangle & 6 & 24 & 228 \\
\hline Majalah Sunda Midang & & 4 & 48 \\
\hline Majalah Cupumanik & & 4 & 48 \\
\hline Tabloid Galura & 1 & 4 & 48 \\
\hline Koran Tribun Jabar & 1 & 4 & 48 \\
\hline Koran Pikiran Rakyat & & & 4 \\
\hline Jumlah Total & & & 354 \\
\hline
\end{tabular}

Untuk ekspresi sastra dalam bentuk sajak tampaknya tidak sesubur karya carpon. Pada majalah Mangle, tidak setiap edisi bisa memuat sajak. Terkadang, pada edisi tertentu harus diselingi dengan pemuatan karya puisi guguritan. Meskipun sesungguhnya, pemuatan sajak lebih produktif dibandingkan dengan pemuatan puisi guguritan. Hal ini dikarenakan tidak setiap penulis sajak mampu menuliskan guguritan. Sementara penulis guguritan akan bisa menuliskan sajak sebaik sang pengarang tersebut menulis guguritan.

Pengarang

Pengarang Sunda pada setiap periode selalu tumbuh dan berkembang. Pertumbuhan dan perkembangan itu cukup membuat tentram para pengamat sastra. Dalam empat dekade terakhir, para pengarang Sunda senantiasa memunculkan generasi baru. Pada dekade 70-an, nama-nama seperti Abdullah Mustappa, Us Tiarsa, Godi Suwarna, Min Resmana, Usep Romli, Taufik Faturohman, Tatang Sumarsono, Etti RS, Aam Amilia, Yosep Iskandar, Eddy D. Iskandar adalah sederetan nama-nama yang sering muncul di media massa 
menyajikan karya-karyanya. Mereka rata-rata mengekspresikan buah pikirannya melalui carpon dan sajak-sajaknya.

Pada dekade 80-an, muncullah nama-nama sastrawan Sunda terbaik seperti Budi Rahayu Tamsyah, Acep Zamzam Noor, Cecep Burdansyah, Sukaesih Sastrini, Hadi AKS, Hidayat Soesanto, Iyas Heriyana, Ano Karsana, Asep Ijudin, Holisoh ME, Mumun Munayah, Cucu Siti Nurjanah, Tetti Hodijah, Yuniarso Ridwan.

Pada dekade 90-an, muncullah nama-nama sastrawan seperti Darpan, Deden A. Azis, Risnawati, Sule Nurharismana, Dian Hendrayana, Imas Rohilah, Ida Daningsih, Dadan Sutisna, Chye Retty Isnendes, Rudi Riadi, Nazarudin Azhar, Deni A. Fajar, serta Dede Syafrudin. Seperti para pendahulunya, para pengarang inipun memublikasikan karyanya berupa carpon dan sajak.

Sepanjang 2000-2010 lahirlah nama-nama Ari Andriansah, Nila Karyani, Endah D. Jenura, Onnok Rahmawati, Toni Lesmana, Ai Koraliati, Sarabunis Mubarok, Tiktik Rusyani, Lugiena De, Deni Hadiansyah, Anita Rohani, Taufik Rahayu, Arif Abdillah, hingga Prayoga Adiwisastra.

Keberadaan para sastrawan tersebut, terikat dan terpelihara dengan adanya komunitas yang khusus mewadahi kegiatan para sastrawan yakni PPSS (Paguyuban Panglawungan Sastra Sunda). Kelompok ini menjadi lembaga yang bisa menaungi para pengarang melalui kegiatan-kegiatan diskusi, saembara, pergelaran sastra, serta pembinaan sastra. Di samping itu terdapat pula kelompokkelompok sastra yang senantiasa menjaga riak kesastraannya melalui kegiatan diskusi dan produksi karya sastra seperti Kelompok Patrem (pengarang wanita), Kelompok (Studi Budaya Sunda) Rawayan (yang merupakan para sastrawan alumni Unpad), Sanggar Sastra Tasik, Panglawungan 13, Sanggar Sastra Majalengka, Sanggar Sastra Cianjur, Sanggar Sastra Purwakarta, Sanggar Sastra Subang. Pun demikian kelompok-kelompok yang ada di lingkungan kampus seperti di Kampus UPI dengan kelompok Pensatrada (Pendidikan Bahasa dan 
Sastra Daerah) melalui majalah Turus-nya serta di Unpad dengan kelompok Pamass (Paguyuban Mahasiswa Sastra Sunda) melalui majalah Tangara-nya.

Regenerasi dalam dunia kepengarangan sastra Sunda biasanya terlahir dengan cara alami serta cara rekayasa. Cara alami biasanya dilakukan karena seorang pengarang banyak membaca dan mengapresiasi secara sendiri-sendiri, lalu mengagumi gaya kepengerangan seseorang (senior). Dan ketika pengarang yang bersangkutan mengekspresikan buah pikiran melalui karya sastranya, seorang pengarang tersebut banyak dipengaruhi gaya dari pengarang yang dikaguminya tadi. Godi Suwarna adalah pengarang yang banyak digandrungi dan dikagumi oleh para sastrawan generasi berikutnya.

Sedangkan cara rekayasa lebih berdasarkan pada regenerasi yang diciptakan melalui media diskusi dan pembinaan oleh para pengarang yang ditunjuk untuk melakukan pembinaan. Biasanya, pembinaan-pembinaan itu berlaku pada lembaga-lembaga yang telah begitu mapan seperti PPSS (Paguyuban Panglawungan Sastra Sunda), LBSS (Lembaga Basa jeung Sastra Sunda), lembaga pendidikan tinggi terutama UPI dan Unpad, atau sanggar-sanggar sastra di setiap daerah.

Stimulan atau Hadiah

Tidak bisa dipungkiri, para pengarang akan termotivasi gairah kepengarangannya jika karyanya didokumentasikan dan dibaca banyak orang. Salah satun upaya itu adalah melalui penerbitan buku. Penerbitan karya sastra itu sendiri tentu saja melalui seleksi yang dikerjakan cukup ketat dan dipilih oleh pihak kurator.

Beberapa buku-buku yang pernah diterbitkan dan dikelola oleh kelompok berkredibilitas tinggi di antaranya buku Salumar Sastra, Karya-karya Pinilih (dikelola oleh LBSS), Nyurup Lambak (kumpulan sajak Pamass Unpad), Lir Cahya Nyorot Eunteung, Kembang-kembang Mangkak (kumpulan fiksi dan non 
fiksi Pensatrada UPI), Guriang Tujuh, Berlian, Surat ti Sawarga, Salikur Carpon Patrem (Patrem), Campaka Mangkak, Heulang Nu Ngajak Béngbat, Néangan Bulan, Kembang Kadengda, Katumbiri (PPSS), Angin Tepiswiring (Panglawungan 13), Ti Pulpén tepi ka Pajaratan Cinta (Girimukti bekerja sama dengan Mekar Parahyangan).

Selain stimuli yang berupa penerbitan buku, motivasi yang mampu meningkatkan gairah kepengerangan adalah karena adanya hadiah sastra; penghargaan atas jerih payah pengarang yang begitu total dalam upaya melahirkan karya-karya sastra terbaiknya.

Hadiah Sastra Rancage. Penghargaan ini merupakan hadiah yang cukup bergengsi di kalangan sastrawan. Bagi sastrawan Sunda sendiri, muncul kesan bahwa siapapun sangat mendambakan dirinya mendapatkan kesempatan untuk dianugerahi penghargaan setinggi itu. Hal itu cukup beralasan, anugerah sastra Rancage diberikan untuk pengarang yang telah melahirkan buku fiksinya. Dan buku fiksinya itu dianggap sebagai buku fiksi terbaik pada kurun satu tahun tertentu. Sedangkan untuk mewujudkan karya-karyana menjadi sebuah buku merupakan upaya yang memerlukan perjuangan cukup panjang dan sangat 'terjal'. Tidak aneh, jika hasil perjuangannya itu berimbas dengan pengharapan penghargaan yang setimpal seperti Hadiah Sastra Rancage.

Hadiah sastra LBSS (Lembaga Basa jeung Sastra Sunda). Penghargaan ini diberikan untuk karya sastra (fiksi dan non fiksi) yang pernah dimuat pada media massa pada kurun satu tahun tertentu. Penghargaan inipun merupakan penghargaan yang sangat didamba-dambakan oleh setiap pengarang. Siapapun yang meraih penghargaan LBSS adalah pengarang yang karyanya mampu menyisihkan ratusan buah karya lainnya yang ditulis oleh berpuluh-puluh pengarang.

Sebagai contoh, untuk menjadi karya carpon terbaik dalam kurun satu tahun tertentu, maka harus berjuang dan bersaing dengan sekitar 350 carpon yang 
dimuat oleh media massa dalam satu tahun. Demikian pula untuk karya puisi, dan karya non fiksi (opini, bahasan, kolom). Maka, ketika sebuah carpon dinyatakan terbaik menurut LBSS, maka carpon itu telah menyisihkan ratusan carpon-carpon lainnya. Jelas ini merupakan penghargaan yang cukup membanggakan bagi pengarang yang kebetulan terpilih untuk meraih penghargaan itu.

Hadiah bulanan carpon pinilih Mangle. Sejak awal tahun 90-an, majalah Mangle dalam setiap bulannya senantiasa memilih satu carpon terbaik dari sekitar 48 carpon yang dimuat dalam kurun satu bulan. Saat ini bentuk penghargaan itu diwujudkan dengan pemberian hadiah berupa uang sebesar Rp 1,5 juta (di awal tahun 90-an hadiah itu sebesar Rp 250 ribu, lalu naik menjadi Rp 500 ribu, naik lagi menjadi Rp 750 ribu, naik lagi Rp 1 juta, hingga akhirnya besarannya kini menjadi Rp 1,5 juta).

Saembara-saembara. Agenda saembara ini memang tidak berlaku pada kurun waktu yang berkesinambungan (rutin). Meskipun demikian kegiatan saembara untuk menjaga riak kesastraan Sunda ini cukup semarak. Adapun lembaga yang kerap melaksanakan kegiatan saembara adalah PPSS yang bekerja sama dengan pihak Disparbud menyelenggarakan saembara penulisan sajak dan carpon; PPSS bekerjasama dengan Teater Sunda Kiwari menyelenggarakan saembara penulisan naskah drama. Paguyuban Pasundan yang menyelenggarakan saembara penulisan carpon di setiap agenda dies natalis-nya. UPI bekerja sama dengan koran Pikiran Rakyat menyelenggarakan saembara menulis carpon. Unpad bekerja sama dengan admin fbs menyelenggarakan saembara menulis fiksimini; Pamass Unpad menyelenggarakan saembara menulis naskah monolog. Lembaga Mekar Parahyangan bekerja sama dengan penerbit Girimukti menyelenggarakan saembara menulis carpon mini.

Diskusi 
Kegiatan diskusi adalah kegiatan yang cukup ampuh untuk menambah wawasan kesastraan serta memelihara riak kesastraan Sunda. Diskusi yang biasa dilakukan dalam pemertahanan kesastraan Sunda terutama dilakukan melalui diskusi konvensional dalam sebuah pertemuan dan perkumpulan, serta diskusi yang dilakukan di dalam dunia maya.

Diskusi dalam bentuk konvensional biasanya membahas sebuah buku (bedah buku) yang baru terbit, mendiskusikan proses kreatif, atau mendiskusikan bagaimana sebuah bentuk karya sastra dikatakan berkualitas tinggi. Biasanya diskusi yang diselenggarakan secara konvensional dilakukan oleh lembagalembaga tertentu (PPSS, LBSS, UPI, Unpad, Redaksi Mangle, Redaksi Galura) serta sanggar-sanggar yang tersebar di daerah. Sedangkan diskusi yang dilakukan dalam dunia maya yakni lebih banyak dilakukan para fesbuker (dalam media facebook).

Pada media facebook, beberapa akun grup yang bertalian dengan kesastraan di antaranya Fiksimini Basa Sunda (fbs), Guguritan, Sisindiran, serta Haiku (Sunda). Para anggota masing-masing akun grup bisa leluasa me-mosting buah pikirannya, dan para admin bisa dan berhak secara leluasa memberikan catatan, kritik yang sifatnya membangun.

Sebagai contoh yang berlaku pada akun grup fbs (fiksimini basa Sunda). Fbs itu sendiri merupakan ekspresi sastra berbentuk prosa yang sangat singkat namun di dalamnya memiliki unsur tingkatan apresiasi (Karyono dkk, 2007:14) seperti surprise, empati, simpati, rasa kagum yang cukup kental. Padahal, volume sebuah fbs dibatasi hanya dengan sekitar 150 (seratus lima puluh) kata saja ${ }^{* *}$. Dalam praktiknya, diskusi atau dialektika yang berlaku di akun grup fbs di facebook, sang admin (administratur, terdiri atas empat orang yang merupakan sastrawan senior atau sastrawan yang dianggap memiliki kredibilitas tinggi dalam

\footnotetext{
** Lihat pengantar Fiksi Mini Sunda (kumpulan terpilih naskah saembara) terbitan Dinas Pariwisata dan Kebudayaan Provinsi Jawa Barat, 2016
}

262 | http://journal.unesa.ac.id/index.php/paramasastra 
Dian Hendrayana, Memelihara Riak Sastra... (hlm. 251-265)

bersastra: Godi Suwarna, Nazarudin Azhar, Hadi AKS, dan Dadan Sutisna) berhak untuk memberikan ulasan atau kritikan terhadap para anggota yang memosting karyanya. Sementara para anggota lainnya bisa memberikan komentar serta tanggapannya berupa dukungan, kritikan, atau bahkan ulasan seperti yang dilakukan admin.

Pola dialektika seperti ini jelas mampu memberikan konstribusi wawasan dan pengalaman berkarya yang cukup positif bagi para anggotanya yang notabene merupakan para penulis pemula. Dari sekian akun grup (sastra) yang ada di facebook, akun grup Fiksimini Basa Sunda (fbs) boleh jadi manjadi akun grup yang cukup berhasil dalam hal 'mendewasakan' pemikiran dan proses kreatif para anggotanya (sebagai pengarang pemula tadi). Indikator keberhasilan fbs mendewasakan para anggotanya adalah tidak sedikit para anggota grup fbs yang kemudian menjadi pengarang carpon yang cukup kuat pada perkembangan selanjutnya. Untuk menyebutkan beberapa nama sastrawan yang merupakan produk 'pendewasaan' di dalam grup fbs di antaranya Erwin Wahyudi, Inda Nugraha, Jejen Jaelani, serta Dewi Ratna Damayanti.

Pola diskusi atau berdialektika perihal kesastraan Sunda diperlihatkan secara kongkret oleh koran Tribun Jabar. Pada koran ini setiap minggunya dimuat satu carpon. Dan pada setiap edisi hari Sabtu, pada koran tersebut dibuka rubrik taraju yang mengakomodasi ulasan atau kritikan khusus pada carpon-carpon yang sebelumnya pernah dimuat pada koran Tribun Jabar tersebut. Dari kegiatan ini, maka banyak bermunculan para pengamat sastra yang berkonsentrasi penuh memberikan kritikan terhadap carpon yang dimuat di Tribun Jabar. Upaya-upaya seperti ini sejatinya membantu menjaga riak kehidupan kesastraan Sunda juga. 


\section{SIMPULAN}

Pemeliharaan riak kesastraan Sunda adalah sebuah upaya sinergisitas antara pengarang, lembaga-lembaga tertentu, serta media-media yang mampu mewadahi ekspresi sastra serta kegiatan sastra. Sinergisitas tersebut dilakukan dengan secara tertib dan sama-sama memiliki misi untuk mengembangkan dan memajukan kesastraan Sunda agar tetap terpelihara.

Untuk upaya regenerasi di kalangan pengarang sastra Sunda, perlu ditradisikan kegiatan diskusi demi menambah wawasan serta memperbanyak pembinaan dari generasi yang terlahir lebih dulu kepada generasi yang terlahir kemudian. Ada baiknya pembinaan seperti ini difasilitasi oleh pihak pemerintah yang memiliki kewajiban mempertahankan keberadaan bahasa, sastra, serta budayanya secara umum, ataupun oleh pihak swasta yang memiliki kepedulian tinggi terhadap dunia sastra.

Kegiatan saembara cukup mampu mebangun semangat bagi para pengarang untuk tetap menulis karya sastra sekaligus meningkatkan kualitas kepenulisannya agar berimbas penghargaan yang diperoleh melalui saembara. Setimuli berupa hadiah-hadiah yang sudah diselenggarakan secara rutin pun cukup ampuh meningkatkan gairah kepenulisan di antara para pengarang.

Peran media massa yang berkepentingan untuk memuat karya dari para sastrawan Sunda harus tetap terjaga pula agar buah pikir dari para sastrawan melalui karya kreatifnya bisa tetap terkespresikan dengan leluasa. ***

\section{DAFTAR PUSTAKA}

Karyono, Tri, dkk. 2007. Apresiasi Bahasa dan Seni. Bandung: Basen Press

Lesmana, Toni, dkk. 2016. Fiksi Mini Sunda. Bandung: Dinas Pariwisata dan Kebudayaan Provinsi Jawa Barat

Rosidi, Ajip. 2013. Mengenal Kesusastraan Sunda (edisi revisi). Bandung: Pustaka Jaya 
Dian Hendrayana, Memelihara Riak Sastra... (hlm. 251-265)

Sukanda, Enip, Dkk. 2016. Riwayat Pembentukan dan Perkembangan Cianjuran. Bandung:

Dinas Pariwisata dan Kebudayaan Provinsi Jawa Barat

Wibisana, Wahyu, dkk (ed). 1992. Lima Abad Sastra Sunda. Bandung: CV Geger Sunten 